\title{
Effect of volatile and non-volatile compounds of Trichoderma spp. on Botrytis fabae the causative agent of faba bean chocolate spot
}

\author{
Barakat F. M. ${ }^{1}$, Abada K. A. ${ }^{1,}$, Abou-Zeid N. M. ${ }^{2}$, El-Gammal Y. H. E. ${ }^{2}$ \\ ${ }^{1}$ Plant Pathology Department, Faculty of Agriculture, Cairo University, Egypt \\ ${ }^{2}$ Plant Pathology Research Institute, ARC. Giza, Egypt \\ Email address: \\ dr_khairy_abada@yahoo.com (Abada K. A.)
}

\section{To cite this article:}

Barakat F. M., Abada K. A., Abou-Zeid N. M., El-Gammal Y. H. E.. Effect of Volatile and Non-Volatile Compounds of Trichoderma spp. on Botrytis Fabae the Causative Agent of Faba Bean Chocolate Spot. American Journal of Life Sciences. Special Issue: Role of Combination Between Bioagents and Solarization on Management of Crown-and Stem-Rot of Egyptian Clover.

Vol. 2, No. 6-2, 2014, pp. 11-18. doi: 10.11648/j.ajls.s.2014020602.12

\begin{abstract}
Antagonistic fungi naturally occurring on faba bean leaf surface were isolated and evaluated for their activity as bioagents for Botrytis fabae the causative agent of chocolate spot disease. Thirty isolates were purified and identified as 26 isolates of Trichoderma species (Trichoderma album, T. aureoviride, T. hamatum, T. harzianum and T. viride) and 4 isolates belonging to the genera of Cladosporium, Gliocladium, Epicoccum and Paecilomyces. The inhibitory effect of these isolates was assessed in vitro against the growth of B. fabae, which decreased it's mycelial growth on PDA plates. The inhibitory effect of Trichoderma spp. ranged between $51.11-77.78 \%$. In addition, T. album (Isolate 2) gave the highest inhibition followed by T. harzianum (Isolate 6). Furthermore, under greenhouse conditions spraying of faba bean plants with any of Trichoderma spp. and Bio- Zeid as a biofungicide, $24 \mathrm{~h}$ before inoculation with B. fabae significantly reduced the severity of the disease after 14 days in the range of $3.0-4 \%$ compared with the control (8.7\%). T. album (Isolate 2$)$ was the highest antagonistic isolate (3.0\%) followed by T. harzianum (Isolate 6) then T. hamatum (Isolate 6) and T. viride (Isolate 2), being 3.24, 3.30 and 3.40\%, respectively. Volatile and non-volatile compounds produced by T. album (Isolate 2) exhibited the highest inhibition to the mycelial growth of B. fabae followed by T. harzianum (Isolate 6).
\end{abstract}

Keywords: Biological Control, Botrytis Fabae, Faba Bean Trichoderma Spp, Volatile and Non-Volatile Compounds

\section{Introduction}

Faba bean (Vicia faba L.) is considered the most important food legume crops in Egypt. The economic importance of faba bean cultivation in the world could be explained by its high nutritional value of vitamins, protein, carbohydrates and some other compounds. Thus, it is a rich available source of food for both human and animals (Sahile et al., 2011). In addition, it improves the soil fertility through nitrogen fixation. Therefore, improving the production of this crop is one of the objectives in agriculture in many countries (Boubekeur et al., 2012).

The total cultivated area with faba bean in Egypt during 2012 growing season reached about 192500 feddan with total production of $1.561 .175 \mathrm{ardab}(\mathrm{ardab}=155 \mathrm{~kg}$ ) at the rate of 8.11 ardab/feddan (Food Legume Statics Dept., Field Crops Res. Instit., ARC.,2012).
Faba bean is liable to be attack by many foliar diseases. However, chocolate spot caused by Botrytis fabae Sard. and Botrytis cinerea Pers. are considered the major destructive diseases affecting the crop, causing serious damage to the plant and decrease of the yield production more than $50 \%$ (Nassib et al., 1991; Bouhassan et al., 2004), especially in the north and middle parts of the Delta in Egypt and several countries in the world (Nassib et al., 1991).

The use of chemical control against this disease sometimes gives good results. However, improper use of fungicides leads mostly to environmental pollution, disasters throughout the world and the phenomena of resistance to $B$. fabae and $B$. cinerea (Brewer and Larkin, 2005). Therefore, to overcome these difficulties, it is urgent to apply alternative safe efficient methods against this disease. 
Biological control is considered an important approach of agricultural biotechnology in recent years for controlling many fungal plant pathogens (Deshmukh et al., 2010). Trichoderma spp. are the most promising and effective bioagents against various plant pathogenic fungi (Fahim et al.,1989; Kumar and Mukerjii, 1996). Trichoderma as antagonist for controlling wide range of microbes was well documented and demonstrated for more than seven decades ago but its use under field conditions came much later (Fahim et al., 1989; Chet et al., 1997) and their mechanism of mycoparasitism is much more complex, that is nutrient competition, hyperparasitism, antibiosis, space and cell wall degrading enzymes (Abd-El-Khair et al., 2010).

Several researchers have reported biological control as an effective method for controlling chocolate spot to reduce the use of fungicides (Hanounik and Hassanein, 1986; Abd El Moiety et al., 1990; Elad and Zimand, 1992; Abou-Zeid et al., 2003; Mahmoud et al., 2012). It was also found that there is a large variety of volatile secondary metabolites produced by Trichoderma such as ethylene, carbon dioxide, hydrogen cyanide, aldehydes and ketones which play an important role in controlling many plant pathogens (Vey et al., 2001; Faheem et al., 2010; Nagendra and Kumar, 2011).

\section{Materials and Methods Plant Materials}

Faba been seeds cv. Giza-429 were obtained from Legume Crops Res. Dept., Agric. Res. Cent., Giza, Egypt.

\subsection{Fungal Isolation Pathogens}

The most aggressive pathogenic fungus of Botrytis fabae (Nubaria isolate), which was used throughout this study was isolated from naturally infected faba bean plants, showing chocolate spot symptoms, cultivated in El-Behera governorate, Egypt. The isolated fungus was identified on the basis of cultural and microscopic morphological characters according to the key given by Jarvis (1977) and Barnett and Hunter (1987).

\subsection{Isolation of the Antagonistic Fungi}

Microorganisms naturally occurring on faba bean leaf surface were isolated from the phylloplane of healthy faba bean plants, collected from different governorate, using dilution plate technique. All the fungal cultures of Trichoderma spp. and the others antagonistic fungi were isolated and purified by hyphal tip technique (Brown, 1924) or single spore method (Hansen, 1926) and then identified on the basis of cultural and microscopic morphological characters (Barnett and Hunter 1987; Bissctt, 1991).

The identification was confirmed by using BiologSystem technique (Biological control of faba bean chocolate spot disease project, Plant Pathol. Res. Instit., A.R.C., Giza, Egypt).

\subsection{Evaluation of Antagonistic Activity of the Antagonistic Fungi ag ain s $t$ B. Fabae}

\subsubsection{Dual Culture Technique}

The antagonistic effect of Trichoderma spp. and the other antagonistic fungi against $B$. fabae in vitro was evaluated using the dual culture technique (Chet, 1987). The virulent isolate of $B$. fabae (El-Nubaria isolate) was cultured, separately, on PDA medium for 7 days at $20 \pm 2{ }^{\circ} \mathrm{C}$. Meanwhile the tested antagonistic fungi were cultured, separately, on PDA medium for 7 days at $25^{\circ} \mathrm{C}$. Disc $(5$ $\mathrm{mm}$ - diameter) from each bio-control fungus was inoculated on the surface of PDA medium in a side of Petri dish. Another disc (5 mm - diameter) of B. fabae, separately, was inoculated at equal distance of the opposite side of Petri dish. Petri dishes inoculated with each pathogenic fungus only served as control. Three Petri dishes were used as replicates. The inoculated Petri dishes were incubated at $20 \pm 2^{\circ} \mathrm{C}$ until the growth completely coverd the plate surface in control treatment. The plates were then examined and linear growth of $B$. fabae was measured to determine the more effective antagonistic isolate of the fungi (AbouZeid and Hassanien, 2000). Antagonistic effect as decrease of the mycelial growth of $B$. fabae, was determined using the following formula:

Antagonistic effect $=\mathrm{C}-\mathrm{T} / \mathrm{C} * 100$

Where: $\mathrm{C}$ is the diameter of mycelial growth of $B$. fabae in control and $\mathrm{T}$ is the diameter of mycelial growth of $B$. fabae in the presence of antagonist.

\subsubsection{Pot Experiment}

Antifungal activity of eighteen Trichoderma isolates ( $T$. album, T. hamatum, T. harzianum, T. aureoviride and $T$. viride) were evaluated for their efficiency in controlling faba bean chocolate spot disease caused by B. fabae (ElNubaria isolate) in pots under artificial inoculation conditions. Faba bean plants c.v. Giza-429 was planted in plastic pots $(25 \mathrm{~cm}$ in diameter). Three replicates of 6 weeks old plants for each treatment were sprayed with Trichoderma spore suspension at the day before artificial inoculation with $B$. fabae spore suspension compared with the bio-fungicide (Bio-Zied). Control plants were sprayed with $B$. fabae only. All pots were covered with polyethylene bags for $48 \mathrm{~h}$ in moist chamber at $20-22^{\circ} \mathrm{C}$ in a greenhouse. Disease severity was recorded 3, 7 and 14 days after inoculation.

\subsection{Effect of Volatile and Non Volatile Compounds on the Linear Growth of B. Fabae}

\subsubsection{Cultural Medium}

The choice of a suitable culture medium is essential for the proper development of the pathogen and the antagonist. PDA medium provides good growing conditions for both $B$. fabae and Trichoderma spp. (Boubekeur et al., 2012). The antagonistic activity in vitro of Trichoderma spp. against $B$. fabae was addressed in two ways: direct and indirect confrontation test. 


\subsection{Effect of Volatile Compounds of the Tested Antagonist (s) on the Linear Growth of B. Fabae}

\subsubsection{Indirect Confrontation Test}

The effect of volatile compounds of T. album and $T$. harizianum on the linear growth of $B$. fabae was demonstrated by the technique of Shirmbock et al. (1994) and Boubekeur et al. (2012). A mycelial disc of $5 \mathrm{~mm}$ diameter of each pathogen and antagonist was put in the center of the Petri-dishes containing PDA medium. The lids were removed aseptically and the bottom of each dish containing the antagonist was placed below another one that contains the pathogen and was enclosed by three layers of parafilm, to prevent the loss of volatile substances (Figure 1). Petri-dishes containing PDA without antagonist served as control. The average diameter of the treatments was measured every day for 6 days of incubation at $20 \pm 2^{\circ} \mathrm{C}$.

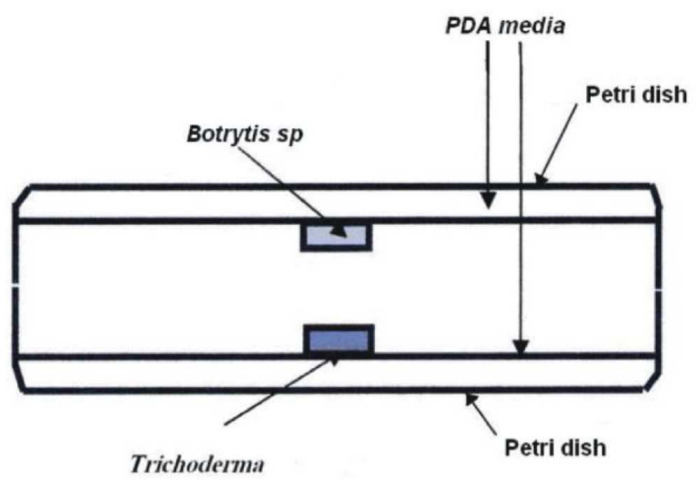

Figure 1. Test of volatile substances influence emitted by Trichoderma spp on the mycelial growth and sporulation of B. fabae.

\subsubsection{Evaluation of Mycelial Growth of B. Fabae}

Evaluation of the inhibition exerted by Trichoderma spp. is estimated by calculating the percentage inhibition of mycelial growth using the following formula:

$$
\mathrm{I}(\%)=(\mathrm{C}-\mathrm{T} / \mathrm{C}) \times 100 \mathrm{n}
$$

$\mathrm{T}$ : Average diameter of colonies in the presence of $\mathrm{n}$ the antagonist. C: Average diameter of the control colonies.

\subsubsection{Evaluation of Sporulation}

Sporulation was estimated for the cultures of Botrytis plates aged 12 days. Ten milliliters of sterile distilled water were added to each Petri-dish containing the fungal growth to release all the spores. The spore suspension was then poured into a beaker filled with sterile distilled water to 50 ml. (Hmouni et al., 1996). Number of spores was counted using the haemocytometer slide under an optical microscope.

\subsection{Effect of Non-Volatile Compounds of the Antagonist(s) on the Linear Growth of B. Fabae}

\subsubsection{Direct Confrontation Test}

Confrontations were performed in vitro using the method of Patel and Brown (1969) in Petri dishes $90 \mathrm{~mm}$ in diameter, containing $15 \mathrm{ml}$ of PDA medium. Agar pellets (5 $\mathrm{mm}$ in diameter), one bearing the strain of Trichoderma to test $B$. fabae were placed following a diametrical axis to 5 $\mathrm{cm}$ a part and distant from the center of the dish (Figure 2). Three Petri dishes for each treatment were used as replicates. The inoculated Petri dishes were incubated at 20 $\pm 2{ }^{\circ} \mathrm{C}$ for 6 days. The indicator consists of an explant of the pathogen on the edge of the dish (Boubekeur et al., 2012).

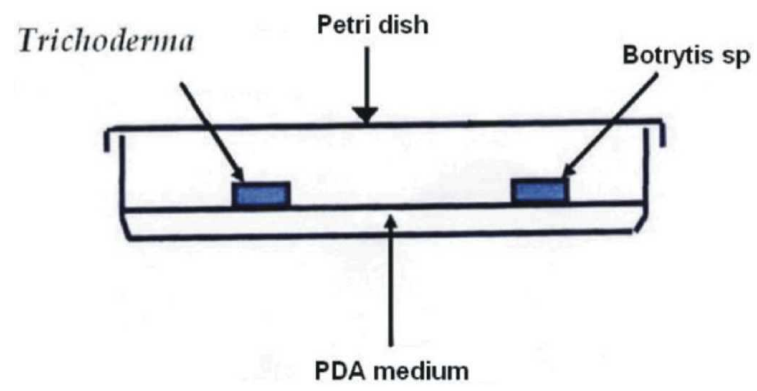

Figure 2. Confrontation between Botrytis and Trichoderma strain by direct contact on PDA medium.

\subsubsection{Evaluation of Mycelial Growth}

Mycelial growth of $B$. fabae was evaluated every $24 \mathrm{~h}$ by measuring the diameter of the Petri dish, the radius of the pathogen on the side of the antagonist. After 6 days of incubation, measurements were made on the width of the zone of inhibition observed between the two colonies.

\subsection{Effect of Non-Volatile (Culture Filtrate) Compounds of the Antagonist (s) on the Linear Growth of B. Fabae}

The bioagents were grown in Potato dextrose broth at $25^{\circ} \mathrm{C}$ with intermittent shaking at $150 \mathrm{rpm}$. The metabolites were collected after 12 days and filtered. The sterilized filtrate was amended to PDA medium to make 5, 10, 25 and $50 \%$ concentration in Petri- plates. The solidified agar plates in triplicates were inoculated at the centre with $5 \mathrm{~mm}$ diameter mycelial disc of the pathogen and incubated at 20 $\pm 2^{\circ} \mathrm{C}$ for 7 days. The Plates without filtrate served as control. The colony diameter was measured and percentage inhibition of radial growth was calculated (Ajith and Lakshmidevi, 2010).

\subsection{Statistical Analysis}

The obtained data were statistically analyzed by analysis of variance (ANOVA) using: Assistant V.7.6 beta (Silva and Azevedo, 2009). Mean comparisons were made using the Least Significant Difference test at $\mathrm{P}<0.05$ test.

\section{Results}

\subsection{Antagonistic Interaction between Botrytis Fabae and Trichoderma spp}

\subsubsection{In Vitro Tests}

The inhibitory effects of the antagonistic fungi against 
the mycelial growth of $B$. fabae in vitro are shown in Table 1. All tested bio-agents decreased the mycelial growth of $B$. fabae isolates markedly to high extent on PDA plates compared with the control. The antagonistic effect of Trichoderma spp. against $B$. fabae was in the range of $51.11-77.78 \mathrm{~mm}$ T. album (Isolate 2) gave the highest effect followed by $T$. harizianum (Isolate 6) then T. harizianum (Isolate 7) and $T$. hamatum (Isolate 6), being 77.78, 72.22, 71.89 and 71.11 $\mathrm{mm}$, respectively.

On the other hand, Paecilomyces lilacinus and Gliocladium catenulatum followed by Cladosporium cladosporioides and Epicoccum nigrum, were weakly effective as they reduced B. fabae growth by $35.56,37.78,38.89$ and $41.11 \mathrm{~mm}$, respectively. Results show that the highest growth inhibition of B. fabae was obtained by T. album (Isolate 2), while the lowest one was obtained by $P$. lilacinus followed by $G$. ncatenulatum then $G$. ncatenulatum, being, 35.56, 37.78 and $41.11 \mathrm{~mm}$ respectively.

\subsection{In Greenhouse Experiment}

\subsubsection{Effect of Some Antagonists on the Severity of Chocolate Spot under Greenhouse Conditions}

Spraying faba bean plants with any of the tested antagonists of Trichoderma spp. and Bio-Zeid as a biofungicide, $24 \mathrm{~h}$ before inoculation with $B$. fabae significantly reduced chocolate spot severity under greenhouse conditions (Table 2). The severity of the disease 14 days after inoculation with Trichoderma spp. was in the range of $3.0-4.9 \%$, compared with Bio-zied and control, being 3.0 and $8.7 \%$ respectively.

T. album (Isolate 2) gave the highest reduction to the disease, 14 days after inoculation (3.0\%), followed by $T$. harizianum (Isolate 6), being 3.24\%, T. hamatum (Isolate 6), being $3.30 \%$ and $T$. viride (Isolate 2 ), being $3.40 \%$. While $T$. aureoviride (Isolate 6), T. viride (Isolate 3), T. aureoviride (Isolate 5) and T. harzianum (Isolate 3) were the lowest effective ones in this regard compared with the other tested antagonists.

\subsubsection{Effect of Volatile Compounds}

Two species of Trichoderma spp. (T. album Isolate 2 and $T$. harzianum Isolate 6) were tested for their ability to produce toxic volatile metabolites against $B$. fabae. Both species produced volatile compounds having significant effect in reducing the linear growth and sporulation of B. fabae. In addition, volatile metabolites produced by T. album (Isolate 2) were more efficient in reducing the mycelial growth and sporulation of B. fabae by 50.38 and $62.55 \%, 6$ and 12 days after incubation, respectively than $T$. harzianum (Isolate 6), being 39.77 and $32.58 \%$, respectively (Table 3 ).

\subsubsection{Effect of Non-Volatile Compounds}

Data of the antagonistic effect of non-volatile compounds of $T$. album (Isolate 2) and T. harizianum (Isolate 6) against the mycelial growth of $B$. fabae in vitro are shown in Table 4. T. album (Isolate 2) resulted in the highest inhibition to the mycelial growth of $B$. fabae, being
$68.8 \%$ followed by T.harzianum (Isolate 6), being $54.4 \%$ inhibition, respectively.

\subsubsection{Effect of Culture Filtrate of the Tested Bioagents Against B. Fabae}

This experiment was carried out to investigate the inhibitory effect of culture filtrate of T. album (Isolate 2) and $T$. harziunum (Isolate 6) at different concentrations on the linear growth of $B$. fabae. Increasing the concentration significantly increased the inhibitory effect of the cultures filtrate.

Data in Table 5 show that all tested culture filtrates of $T$. album (Isolate 2) and T. harziunum (Isolate 6) at the different concentrations significantly decreased the linear growth of B. fabae (Nubaria isolate) in comparison with control treatment. All the tested culture filtrates (nonvolatile compound) of T. album (Isolate 2) and T. harziunum (Isolate 6) at the different concentrations significantly reduced the mycelial growth of $B$. fabae being 66.58 and $71.50 \mathrm{~mm}$, respectively compared with control $(90 \mathrm{~mm})$.

\section{Discussion}

Table 1. Effect of different antagonistic fungi on the linear growth of $B$. fabae (Nubaria isolate) on PDA plates, 6 days after incubation at $20 \pm 2{ }^{\circ} \mathrm{C}$.

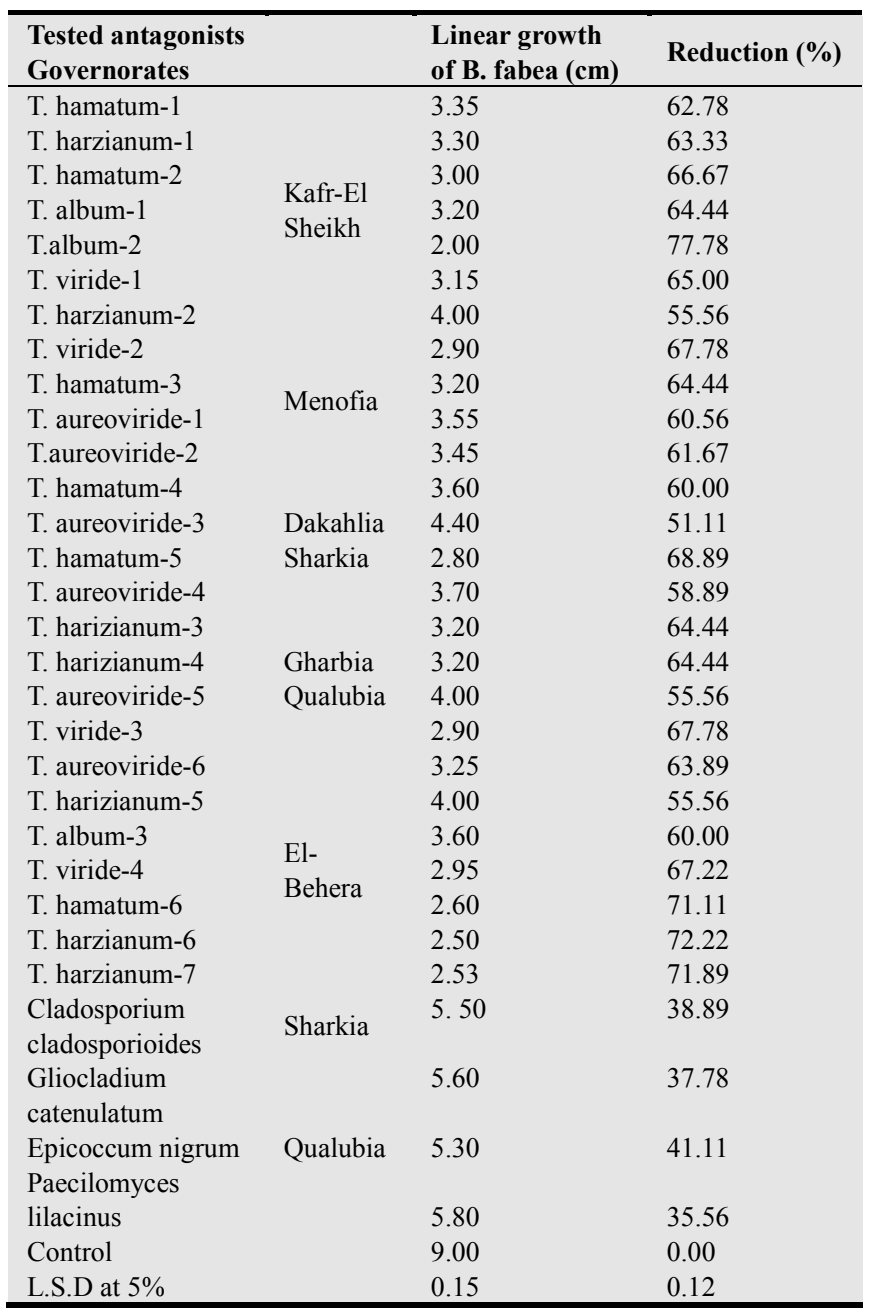


Some microorganisms may play an important role in the controlling of some plant diseases. The obtained data showed that there was a promising antagonistic species of fungi prevalent on faba bean leaves, which could be exploited for the control of chocolate spot (Abd EI-Moity et al., 1990). The genus Trichoderma comprises a great number of fungal strains that act as biocontrol agents (Abou-Zeid and Hassanien, 2000). All the tested antagonistic fungi decreased the mycelial growth of $B$. fabae on PDA plates. The antagonistic isolates of Trichoderma spp. over-come and inhibited B. fabae

Table 2. Effect of different antagonistic fungi on the severity of chocolate spot under greenhouse condition.

\begin{tabular}{|c|c|c|c|c|}
\hline \multicolumn{5}{|c|}{ Disease severity after days (\%) } \\
\hline Tested antagonists & 3 & 5 & 7 & 14 \\
\hline T. harzianum-1 & 1.10 & 5 & 7 & 4.10 \\
\hline T. hamatum-2 & 1.60 & 2.13 & 3.12 & 3.65 \\
\hline T. album-2 & 0.50 & 1.75 & 2.70 & 3.00 \\
\hline
\end{tabular}

\begin{tabular}{|c|c|c|c|c|}
\hline \multicolumn{5}{|c|}{ Disease severity after days (\%) } \\
\hline Tested antagonists & 3 & 5 & 7 & 14 \\
\hline T. viride-1 & 1.40 & 1.10 & 2.05 & 4.20 \\
\hline T. viride-2 & 1.30 & 2.38 & 2.39 & 3.40 \\
\hline T. hamatum-3 & 0.60 & 1.38 & 2.39 & 3.50 \\
\hline T.aureoviride-2 & 0.90 & 1.50 & 2.50 & 3.60 \\
\hline T. hamatum-4 & 1.60 & 1.65 & 2.63 & 4.20 \\
\hline T. aureoviride- 3 & 1.26 & 2.50 & 3.35 & 4.10 \\
\hline T. aureoviride- 4 & 1.80 & 2.38 & 3.24 & 3.66 \\
\hline T. harzianum-3 & 1.40 & 1.75 & 2.68 & 4.70 \\
\hline T. aureoviride-5 & 1.80 & 2.50 & 3.60 & 4.80 \\
\hline T. viride- 3 & 1.90 & 2.75 & 3.78 & 4.90 \\
\hline T. aureoviride- 6 & 1.90 & 2.80 & 3.85 & 4.90 \\
\hline T. album-3 & 2.10 & 2.85 & 3.88 & 4.60 \\
\hline T. viride- 4 & 2.00 & 2.75 & 3.68 & 4.20 \\
\hline T. hamatum-6 & 0.45 & 2.13 & 3.17 & 3.30 \\
\hline T. harzianum-6 & 0.40 & 1.25 & 2.28 & 3.24 \\
\hline Bio-Zeid & 0.80 & 1.22 & 2.23 & 3.00 \\
\hline Control & 3.40 & 1.85 & 2.22 & 8.70 \\
\hline L.S.D at $5 \%$ & 0.13 & 4.60 & 6.65 & 0.18 \\
\hline
\end{tabular}

Table 3. Effect of volatile compounds of T. album (Isolate 2) and T. harizianum (Isolate 6) on the linear growth and sporulation of B. fabae, 6 and 12 days after incubation at $20 \pm 2^{\circ} \mathrm{C}$.

\begin{tabular}{|c|c|c|c|c|}
\hline The antagonistic fungus & Linear growth in (mm) & Growth inhibition (\%) & No. of spores/ml x 106 & Spore inhibition (\%) \\
\hline T. album-2 & 44.66 & 50.38 & 1.00 & 62.55 \\
\hline T. harzianum-6 & 54.21 & 39.77 & 1.80 & 32.58 \\
\hline Control & 90.0 & 0.00 & 2.67 & 0.00 \\
\hline L.S.D at $5 \%$ & 2.11 & 3.12 & 0.323 & 2.46 \\
\hline
\end{tabular}

Table 4. Effect of non-volatile compounds produced by T. album (Isolate 2) and T. harzianum (Isolate 6) on the linear growth of B. fabae, 6 days after incubation at $20 \pm 2^{\circ} \mathrm{C}$.

\begin{tabular}{|c|c|c|}
\hline The antagonistic fungus & Linear growth in (mm) & Growth inhibition (\%) \\
\hline T. album-2 28.0 & & 68.8 \\
\hline T. harzianum-6 41.0 & & 54.4 \\
\hline Control 90.0 & & 0.00 \\
\hline L.S.D at $5 \% 2.1$ & & 1.11 \\
\hline
\end{tabular}

Table 5. Effect of different concentrations of culture filtrate of antagonists on the linear growth (mm) of $\mathrm{B}$. fabae, 6 days after incubation at $20 \pm 2{ }^{\circ} \mathrm{C}$.

\begin{tabular}{|c|c|c|c|c|c|}
\hline The antagonistic fungus & Linear growth in (mm) Growth inhibition (\%) & No. of spores/ml 106 & Spore inhibition $(\%)$ & $\mathbf{X}$ & Mean \\
\hline T. album-2 & 50 & 37.5 & 25 & 12.5 & 66.58 \\
\hline T. harzianum-6 & 54.67 & 62.33 & 71.33 & 78.0 & 71.50 \\
\hline Control Mean & 60.33 & 65.67 & 77.67 & 83.33 & 90.00 \\
\hline L.S.D at $5 \%$ & 90.00 & 90.00 & 90.00 & 90.00 & \\
\hline Antagonists (A) & 0.64 & & & & \\
\hline Concentration (C) A & 0.72 & & & & \\
\hline $\mathrm{x} C$ & 0.98 & & & & \\
\hline
\end{tabular}

growth in the range of $51.11-77.78 \%$. T. album-2 gave the highest growth inhibition followed by $T$. harzianum- 6 then $T$. harzianum-7 and T. hamatum-6. This may due to the release of toxic metabolites into the medium (Akhtar, 1982), also it may be due to competition for space and nutrients with $B$. fabae, because the pathogen requires exogenous nutrients for germination and germ- tube elongation over a period of several hours on the phyllosphere before penetrating the host plant (Dubos and Bulit, 1981). Indeed, the confrontation test whether a direct way of culture medium or remotely showed inhibition of growth and sporulation of the pathogen. If there is contact between $T$. album and T. harzianum, the pathogen, Trichoderma colonies invade those $B$. fabae. When the pathogen is confronted in a direct way of culture medium, Trichoderma spp. breakdown the mycelium and cause a reduction of sporulation on the edge of the zone of inhibition due to secretion of antibiotic substances circulating in the culture medium.

Saber et al. (2009) reported that all of the tested fungal antagonists showed reasonably higher growth rate than the pathogen $B$. fabae, which has a daily growth rate in the range of $15-35 \mathrm{~mm} /$ day. These might be producing antibiotics or extracellular enzymes, which inhibited the growth of the pathogen.

Results indicated that, spraying faba bean plants $24 \mathrm{~h}$ before inoculation with the tested pathogen with any of the tested Trichoderma spp. and Bio-Zeid as a biofungicide 
significantly reduced chocolate spot severity compared with Bio-Zeid and control. T. album-2 was the high antagonistic isolate followed by $T$. harizianum- 6 , T. hamatum- 6 and $T$. viride-2. The bio-mass of the pathogen was reduced in the presence of Trichoderma spp. This may be due to an effect on germ-tube elongation and to a lesser extension of germination rate (Zimand et al., 1996).

Trichoderma spp. are known to control pathogens either indirectly by competing for nutrients and space, modifying the environmental conditions, or promoting plant growth and enhancing plant defensive mechanisms and antibiosis, or directly by inhibition of growth and sporulation of the pathogen mechanisms such as mycoparasitism and enzyme production (Zimand et al., 1994; Bouhassan et al., 2004).

The earlier studies also revealed that antimicrobial metabolites produced by Trichoderma spp. are effective against a wide range of phytopathogenic fungi, e.g. B. fabae, Fusarium oxysporum, Rhizoctonia solani, Curvularia lunata, Bipolaris sorokiniana and Colletotrichum lagenarium (Fahim et al., 1989; Svetlana et al., 2010).

The obtained results showed that, T. album-2 exhibited maximum growth inhibition to the mycelial growth of $B$. fabae followed by $T$. harzianum- 6 compared to the control. This inhibition was more pronounced in the case of T. album-2. It appears that despite the absence of direct contact between Trichoderma spp. and isolates of $B$. fabae, the first may have an inhibitory activity on the development of colonies of B. fabae. This could be explained by the ability of Trichoderma spp. to produce volatile substances that are able to limit and even stop the development of the pathogen. Also it is found that there is large variety of volatile secondary metabolites produced by Trichoderma such as ethylene, carbon dioxide, hydrogen cyanide, aldehydes and ketones, which play an important role in controlling the plant pathogens (Vey et al., 2001; Faheem et al., 2010; Nagendra and Kumar, 2011).

The volatile substances caused significant inhibition to the sporulation of the causal fungus compared to the control. These observations suggested the possibility of secretion of antagonistic substances that diffuse into the culture medium, which cause lysis of the mycelium and spores of the pathogen.

The non-volatile secondary metabolites of Trichoderma species were found more effective in suppressing the mycelial growth of B. fabae. T. album-2 exhibited the highest effect on the mycelial growth of $B$. fabae followed by $T$. harzianum- 6 . After 7 days of confrontation, the colonies of Trichoderma spp. completely overlapped and covered the colonies of the B. fabae due to their mycoparasitism. Elad et al. (1993) described the action of T. harzianum and $T$. hamatum on B. fabae. Trichoderma spp. attacks the host by winding the mycelium around the host hyphae. Subsequently, the mycoparasite penetrates the host cells and uses the cytoplasmic contents.

In this respect, culture filtrates of T. album-2 was the most effective in reducing the linear growth of $B$. fabae followed by $T$. harziunum- 6 compared with control treatment. The non- volatile secondary metabolites from Trichoderma species (T. album-2 and T. harziunum-6), were found more effective in suppressing the mycelial growth of $B$. fabae when compared to volatile compounds. In this respect, culture filtrate of $T$. album-2 was the most effective in reducing the linear growth of $B$. fabae followed by $T$. harziunum- 6 in this respect.

\section{Conclusion}

This study showed that there were promising antagonistic species of fungi prevalent on faba bean leaves, which can be exploited for the control of chocolate spot. The genus Trichoderma comprises a great number of fungal strains that act as biological control agents for the control of plant diseases and for their ability to increase plant growth, the antagonistic properties of which are based on the activation of multiple mechanisms. The antagonistic nature may be due to antibiosis, nutrient competition and cell wall degrading enzymes. The present study clearly showed the effect of the two antagonistic strains of Trichoderma isolates (T. album and T. harzianum), against $B$. fabae. Volatile and non-volatiles compounds produced by selected Trichoderma spp. drastically reduced the mycelium growth and spore production of B. fabae in-vitro. Based on the present investigation a new strategy will be developed for controlling chocolate spot disease on faba bean in vivo.

\section{Acknowledgment}

The author would like to thank all members of Biological Resource Center Standard (BRCS) Unit, Plant Pathology Research Institute ARC. This research was implemented and funded by Biological Control of Chocolate Spot Disease on Faba bean Project, Plant Pathology Research Institute ARC.

\section{References}

[1] Abd EI-Moity TH, Abou-Zeid NM, Tawfik AE (1990). Correlation between microbial populations in phylloplane of faba bean varieties and their reaction to Botrytis fabae. Agric. Res. Rev. 68 (3): 433- 441.

[2] Abd-El-Khair HR, Khalifa KM, Karima HE, Haggag (2010). Effect of Trichoderma spp. on damping off diseases incidence, some plant enzymes activity and nutritional status of bean plants. J. American Sci., 6 (9):486-497.

[3] Abou-Zeid NM, Hassanien AM (2000). Biological control of chocolate spot disease (Botrytis fabae Sard.) in faba bean in Egypt. Phytophathology, 90:1182.

[4] Abou-Zied NM, Hassanein AM, EL-Behery MH (2003). Biological control of damping -off and root- rot diseases of faba bean caused by Rhizoctonia in faba bean, lentil and chickpea and chocolate spot disease in faba bean / ICARDA / NVR SRP. Cairo. Egypt. viil-66p. ISBN : 977-302-0738pp-49-52. 
[5] Ajith PS, Lakshmidevi N (2010). Effect of volatile and nonvolatile compounds from Trichoderma spp. against Colletotrichum capsici incitant of Anthracnose on Bell. Nature and Science., 8 (9):265-269.

[6] Akitar CM (1982). Investigation of the biological control of Rhizoctonia solani and Fusarium oxyspomm f.sp. lentil rootrot and wilt disease in cotton and linseed crops, respectively. Final report of project No.PK-ARS 83, AAIMRIV A, Fasulabed.

[7] Barnett HL, Hunter BB (1987). Illustrated Genera of Imperfect Fungi. (4 ${ }^{\text {th }}$ ed.). MacMillan Pub. Co., New York, U.S.A., 218 PP

[8] Bissett J. (1991). A revision of the genus Trichoderma.W: Infragenic classification. Can. J. Bot., 69:2357-2317.

[9] Boubekeur SB, Mahiout D, Benzohra IE, Benkada MY (2012). Antagonism of three Trichoderma species against Botrytis fabae and B. cinerea, the causal agents of chocolate spot of faba bean (Vicia faba L.) in Algeria. World Appl. Sci. J., 17 (3): 278283.

[10] Bouhassan A, Sadiki M, Tivoli B (2004). Evaluation of a collection of faba bean (Vicia fabae L.) genotypes originating from the Maghreb for resistance to chocolate spot (Botrytis fabae) by assessment in the field and laboratory. Euphytica 135:55-62.

[11] Brewer MT, Larkin RP (2005). Efficacy of several potential biocontrol organisms against Rhizoctonia solani on potato. Crop Protection, 24: 939-950.

[12] Brown W (1924). Two mycological methods: 11.A method of isolating single strains of fungi by cutting a hyphal tip. Ann. Bot., 38: 404

[13] Chet I, Inbar J, Hadar I (1997). Fungal antagonists and mycoparasites. In: The Mycota IV: Environmental and Microbial Relationships. Wicklow DT and Soderstorm B, eds. pp 165-184.

[14] Chet I (1987). Trichoderma-application, mode of action and potential as a biocontrol agent of soil borne plant pathogenic fungi: Chet I., (Ed). Innovative Approaches to Plant Disease Control. John Wiley as sans. New York. pp137-160.

[15] Dubos B, Bulit J (1981). Filamentous fungi as biocontrol agents on aerial plant surfaces Ill: BlackmanJ.P. (ed). Microbial Ecology of the phyl/oplalle. Academic Press, London, pp 353-356.

[16] Deshmukh AJ, Mehta BP, Patil VA (2010). In vitro evaluation of some known bioagents to control $C$. gloeosporioides Penz, and Sacc, causing Anthracnose of Indian bean. Int. J. Pharma and Bio sci. 1 (2) pp 1-6

[17] Elad Y, Zimand G (1992). Integration of biological and chemical control of grey mould. In: N. E. Malathrakis, and B. Williarnson (eds) Recent Advances ill Botrytis Research. Pudoc Scientific Publishers, Wageningen, Netherlands. . pp 272-276.

[18] Elad Y., Zimand G., Zoqs Y., Zuriel S., and Chet I., (1993). Use of Trichoderma harzianum in combination or elternation with fungicides to control cucumber gray mold (Botrytis cinerea) under commercial green house conditions. Plant Pathology. 42:324-332
[19] Faheem A, Razdan VK, Mohiddin FA, Bhat KA, Sheikh PA (2010). Effect of volatile metabolites of Trichoderma Spp. against seven fungal plant pathogens in vitro. J. Phytol. 2(10): $34-37$

[20] Fahim MM, Attia MF, Okasha AK, Abada KA ( 1989). Trichoderma as a biocontrol agent against root and crownrots of strawberry. Egypt. J. Phytopathol., 21 (2): 139-148 .

[21] Hanounik SB, Hassanein AM (1986). Inhibition of Botrytis fabae in the phyllosphere of Vicia fabae leave. Fabis Newsletter 16:41-44.

[22] Hansen HN (1926). A simple method of obtaining single spore cultures. Science (N.S.), 64: 384.

[23] Hmouni A, Hajlaoui MR, Mlaiki A (1996). Resistance de Botrytis cinerea aux benzimidazoles et aux dicarboximides dans les cultures de tomate en Tunisie. OEPP /EPPO Bulletin, 26: 697705.

[24] Jarvis WR (1977). Botryotinia and Botrytis species: Taxonomy, Physiology and Pathogenicity, pp. 33-34. Monograph 15, Research Branch, Canada Department of Agricultural Science, Ottawa.

[25] Kumar RN, Mukerji KG (1996). Integrated disease management future perspectives, pp. 335-347. In: K.G. Mukerji, B. Mathur, B.P. Chamala and C. Chitralekha (Eds.), Advances in Botany.APH Publishing Corporation, New Delhi.

[26] Nagendra B, Prasad, Kumar MR (2011). Effect of nonvolatile compounds produced by Trichoderma spp. on growth and sclerotial viability of Rhizoctonia solani, incitant of sheath blight of rice. Indian J. Fundamental Appl. Life Sci.1 (2) 37-42.

[27] Nassib AM, Khalil SA, El-Botai MA, Radi MM (1991). In: Nile Valley Regional program on Cool Season Food Legumes and Cereals.1990/91.Annual Report, Egypt. Cairo: ARC /ICARDA.

[28] Mahmoud NA, Ashrei AAM, Mekhemar GAA (2012). Evaluation of some products in controlling chocolate spot of faba bean and their effect on the growth and yield parameters. Egypt .J. Agric. Res., 90 (3): 991-1000.

[29] Patel JJ, Brown ME (1969). Interactions of Azobacter with rhisosphere and root-surface microflora. Plant and Soil, 31: 273281

[30] Saber WIA, Abd El-Hai KM, Ghoneem KM (2009). Synergistic effect of Trichoderma and Rhizobium on Both biocontrol of chocolate spot disease and induction of nodulation physiological activities and productivity of Vicia faba. Res. J. Microbiol 4:286-300.

[31] Sahile S, Sakhuja PK, Fininsa C, Ahmed S (2011). Potential antagonistic fungal species from Ethiopia for biological control of chocolate spot disease of faba bean. Syria African Crop Science J. Afr. Crop Sci. Society, 19 (3): 213 - 225.

[32] Schirmbock M, Lorito M, Wang YL, Hayes CK, ArisanAtlac I, Scala F, Harman GE, Kubicek CP (1994). Parallel formation and synergism of hydrolytic enzymes and peptaibol antibiotics, molecular mechanisms involved in the antagonistic action of Trichoderma harzianum against phytopathogenic fungi. Applied Environmental Microbioliogy, 60: 4364-4370. 
[33] Svetlana Z, Stojanovic S, Ivanovic Z, Gavrilovic V, Tatjana P, Jelica Balaz (2010). Screening of antagonistic activity of microorganisms against Colletotrichum acutatum and Colletotrichum gloeosporioides, Archives of Biological Science., Belgrade, 62(3) :611-623.

[34] Silva FA. Azevedo CA (2009). Principal Components Analysis in the Software Assistat-Statistical Attendance. In: Worled Congress on Computers in Agriculture, 7 Reno-NVUSA: American Society of Agricultural and Biological Engineers.
[35] Vey A, Hoagland RE, Butt TM, (2001). Toxic metabolites of fungal biocontrol agents. Fungi as Biocontrol Agents: Progress, Problems and Potential. Butt T.M, Jackson C and $\mathrm{N}$, eds, pp 311346. CAB International, Bristol.

[36] Zimand G, Elad Y, Chet I (1996). Effect of Trichoderma harzianum on Botrytis cinerea pathogenicity. Phytopathology, 86: 11, 12551260. 